\title{
Examining the Effect of Online Gaming Addiction on Adolescent Behavior
}

\author{
Maha AlDwehy ${ }^{1}$, Dr. Hedia Zardi ${ }^{2}$ \\ Department of Computer Science \\ College of Computer, Qassim University \\ Buraydah, Saudi Arabia
}

\begin{abstract}
It exceeds daily rates of Internet use among adolescents compared to adults' use of the Internet, as it was monitored that the number of adolescents on the Internet is increasing all over the world. Today, as a result of the ease of access to the Internet in the world, most adolescents' access to the internet world is easier and more common. In this paper, we review some studies that explain the behavior of adolescents while gaming online and its effects. There are some statistics to determine the impact of the Internet on teenagers. The study reviews past studies on adolescent behavior and privacy with a potential impact on adolescent behavior, which has become one of the most important problems. We focused on exploring online game addiction concerns and their effects on teens' behavior. The purpose of this type of study is to determine the objective and examine this study within the backdrop of social reality. This study employed a quantitative methodology. We have selected this methodology because it has been proven to be reliable and has sound construct validity. The data was analyzed using the SPL smart tool and the main objective of this study was to investigate adolescent's behavior in terms of their addiction to online games, and to study parents' awareness of the dangers of online games for their children. The study explored various factors that can influence addiction fears and examines their effects on adolescent behavior and contributed to the literature by identifying correlation factors and addressing this gap by applying through SEM application specifically the Smart PLS tool.
\end{abstract}

Keywords-Online gaming addiction; adolescent behavior on internet; privacy

\section{INTRODUCTION}

\section{A. Adolescent Behavior on the Internet}

The rapid progress in technology today has brought about a major social transformation in all areas of society, and as a result of the use of the Internet for adults as well as adolescents at the same level of facilities and interaction, whether through a communication or online games or other [1]. The results of the analysis showed that the number of adolescents exceeds the number of adults, because there is a rapid increase in the number of teenagers around the world, and the results indicate that they are more vulnerable, as they are constantly exposed to inappropriate con- tent for them [1]. Today this generation is called a technical generation, teens spend a lot of time gaming online and interacting on social networking. As a result of the increased accessibility of the Internet in developed countries, the numbers of Internet callers increased, in turn, to a number that cannot be registered today [2]. A complete technological revolution has occurred during the past two decades and a new era for childhood has emerged, the digital age. Which made many researchers focus on their studies on the impact of the use of the Internet in general, and for adolescents in particular, where their research touched on emotional and psychosocial aspects [2]. As they focus on the extent of the negative effects of adolescent addiction to use the Internet [3]. The results of the paper showed that, in the year 2009-2010, approximately $93 \%$ of Internet users in the United States are adolescents [3] and the number of Internet users from adolescents in Europe constitutes $60 \%$ as the study results showed that they spend their time using the Internet in games via the Internet [2]. And still, to this day, the number of teenagers who use the Internet are increasing, and as a result, the fears are increasing.

Where the authors of the study found that more than half of adolescents aged 9-19 have a local internet connection worse, whether through schools or regular Internet users [1]. This number is still increasing, and even children between the ages of 5 and 8 have a local internet connection. Society has given more attention to protecting adolescents and children from external physical hazards, and they have not paid attention to technological interaction [2], [4] and [5]. Computer and artificial intelligence experts say there is an emotional connection between teens and electronic games around the world, as they seem to know in their depths that they are the computer generation [15]. As a result, today the methods of collecting information have become easier through the use of data acquisition and extraction systems. Numerous studies have shown that adolescents are easy targets for information col- lectors because they are often under-conscious. Data collection for adolescents occurs when there is an interaction between them and the fictional character. Among the factors that affect adolescents, social impact, more than half of the parents believe that the child tends to isolate as a result of using the Internet, especially in online games, so parents have a responsibility to think about whether there is harm or benefit when their children participate in society from During the internet and interpersonal relationships, in addition to focusing on social activities, previous studies indicated that there is a decrease in social activities for individuals who spend more time on the Internet [15]. There is also the problem of the health factor, where attention must be paid to the impact of adolescents' mental and physical health as a result of their use of the Internet, where, as it is clear, the obesity factor has increased with the invasion of the Internet in Western society [15]. The results of the studies showed that the rate of obesity has multi 
plied the number of times over the rate found in the sixties and the beginning of the seventies, in addition to inactivity and lack of movement, the child spends long hours up to more than five hours per day either on the computer or mobile [16]. Also, with regard to their health and safety, great attention must be paid to knowing the people they meet through the network, in terms of misfortune in online games or social media. It is important to educate teenagers and draw their attention that there is a hidden danger and must be careful throughout and take all precautions to avoid the danger [16].

\section{B. Online Games}

Online games are an important factor in affecting adolescent behavior, as it greatly affects their behavior and may lead to excessive addiction [3]. Concerns have been expressed about online gaming, there is a growing concern that information about them can be collected through online games, which is becoming an increasingly important issue today [3]. In addition, there is a risk of internet content that may be harmful to teenagers as well as children [17]. Teens may place their faith in these technologies without being fully aware of the risks and implications of this, the content may carry violent material that supports hate, or the teenager may be exposed to an illegal content, wrong information, difficult and dangerous games that affect their thinking and behavior [3]. In fact, $85 \%$ of parents think that Internet content (photos, games, videos, etc.) pose a greater risk to teenagers and more dangerous than TV [3].

\section{Information Privacy}

This is personal privacy and there is also information privacy [6]. Many authors have provided different meanings and definitions of the word privacy in all its forms, but there is no standardized and specific description covering all aspects of this term [6]. However, it was agreed that privacy is one of the most important ethical issues for the information age [7]. As a result of adolescents entering the online world, there are increasing concerns about disclosing their privacy [7]. So privacy is a critical issue, and it exceeds adolescents because they are the easiest prey for their privacy to be violated by unauthorized persons or people with malicious intent [8]. They are vulnerable to sharing their personal data easily compared to more conscious adults and are more difficult to provoke compared to adolescents [9]. If privacy refers to the collection of information and unauthorized use, as well as errors of improper access to the control of the individual when issuing personal information [11]. Privacy in terms of disclosure of personal information is another aspect to consider. It is self-disclosure of personal information [13]. When people communicate with each other, this process is called self-disclosure [13]. Intimacy and sensitivity are two advantages of information that seem important to disclosing information, and disclosure of privacy relates to the level and type of information that individual wishes to dis- close to another [13]. The paper [10] specifically found that users disclosed their birth date of $87.8 \%$, and the profiles they examined contained an image of about $90.8 \%$ and $50.8 \%$ included their current residence. In addition, 39.9\% included a phone number, and most users revealed their full names [10]. In socially based Internet domains, privacy disclosure can also be seen online. One such medium is games [10]. Because such games were controlled by youth and adolescents between the ages of 13 and 19 [10]. In online social networks, when an individual's private information is disclosed about a person, the $\mathrm{P}$ of his / her boyfriend's FP is disclosed to another FFP (FFP is not a friend of $\mathrm{P}$ ), then it is called a privacy leak [11]. Privacy leaks may remain all the time, while personal information is shared by interacting with friends [14]. Some of those who want to obtain user information try to use methods to obtain private information from any possible way (sometimes legal and sometimes illegal) to obtain this desired information do not give up and this is a big problem [12] [14].

\section{METHODS}

\section{A. Experiment}

1) Data collection: In this study a procedure was used for the data collection design process, which includes sampling technique, target population and questionnaires.

2) Target population: We chose to be a sample of parents, because they are more likely than others to be concerned about the impact of online games on their children's behavior, especially in adolescence, in addition to that they are knowledgeable about adolescent behavior online and have easy access to dis- tribute the questionnaire. When we talk about their children, they pay special attention to this topic. Sampling techniques: This study focuses on the method of the online survey. Whereas, as we dis- cussed above, we will collect data from parents as they are concerned about adolescent behavior. The questionnaire will be available through a URL: Put the link on Twitter (Retweet). Send the link via groups on WhatsApp.

\section{B. Questionnaire}

The questionnaire for this study was created by Google Docs. Various types of questions were asked which are multiple-choice, select multiple answers, yes or no questions, agree or not, and scale questions). The questions of this study were written in English and Arabic to obtain the largest possible participation from parents. At the beginning of the questionnaire we added a pre-test questionnaire in order to understand the project and its questions (Table I), and then we focused on our hypothesis (Addiction concerns, Psychological effect, Risk, parental control, subjective norm, content) when we developed the questionnaire. This study formulated questions for the questionnaire (as shown in Table II) and asked questions to know the background of the participants.

\section{Pre-Test Questionnaire}

The questionnaire should not take more than 10 minutes to complete. 
TABLE I. SAMPLE OF QUESTIONNAIRE

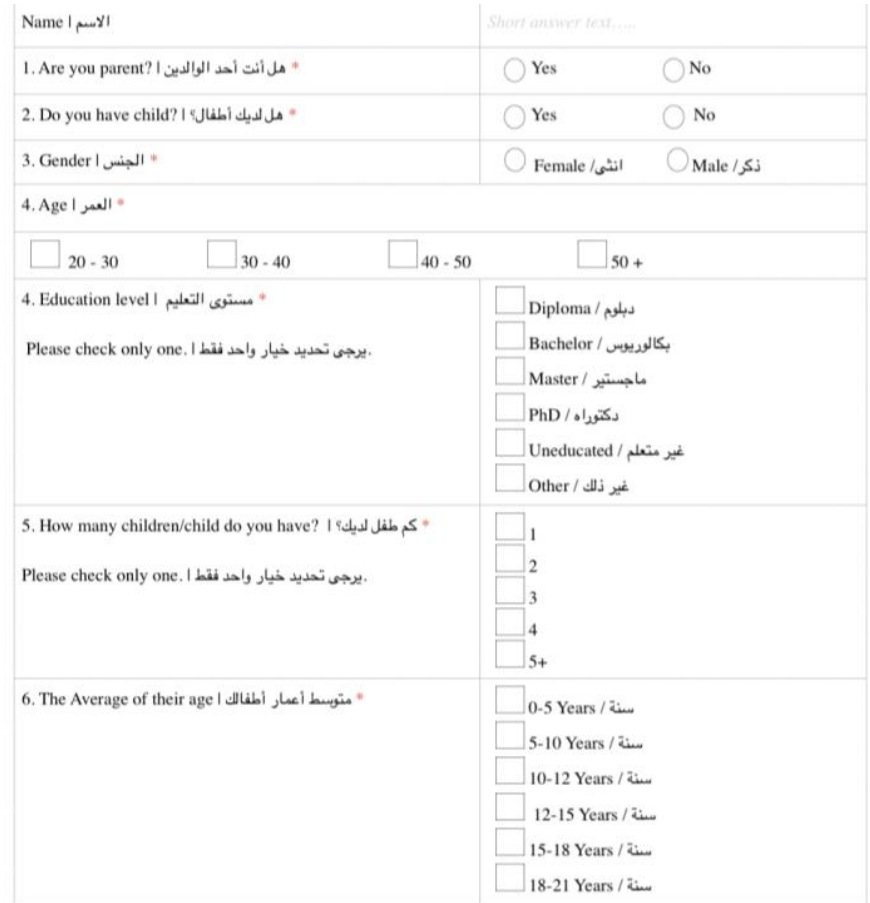

\section{Post Questionnaire}

Please rate your agreement with the following statements on a scale of 5 .

TABLE II. SAMPLE OF QUESTIONNAIRE 2

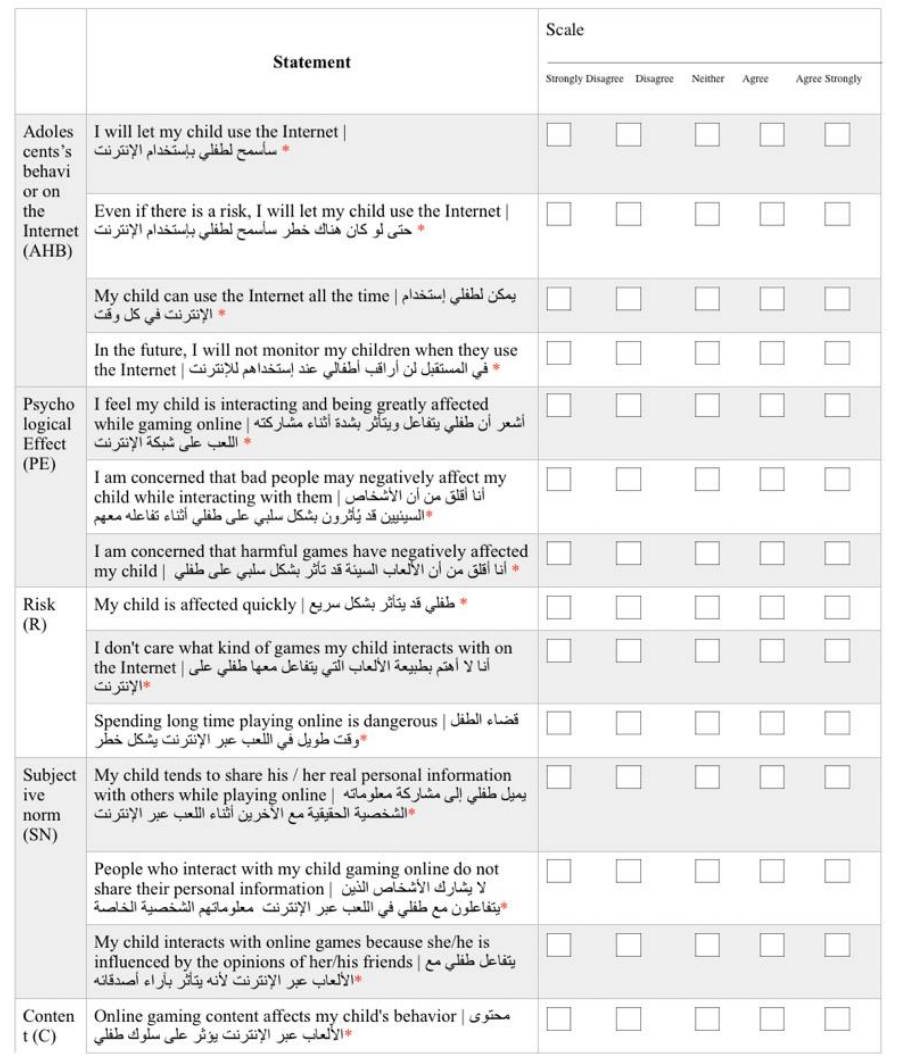

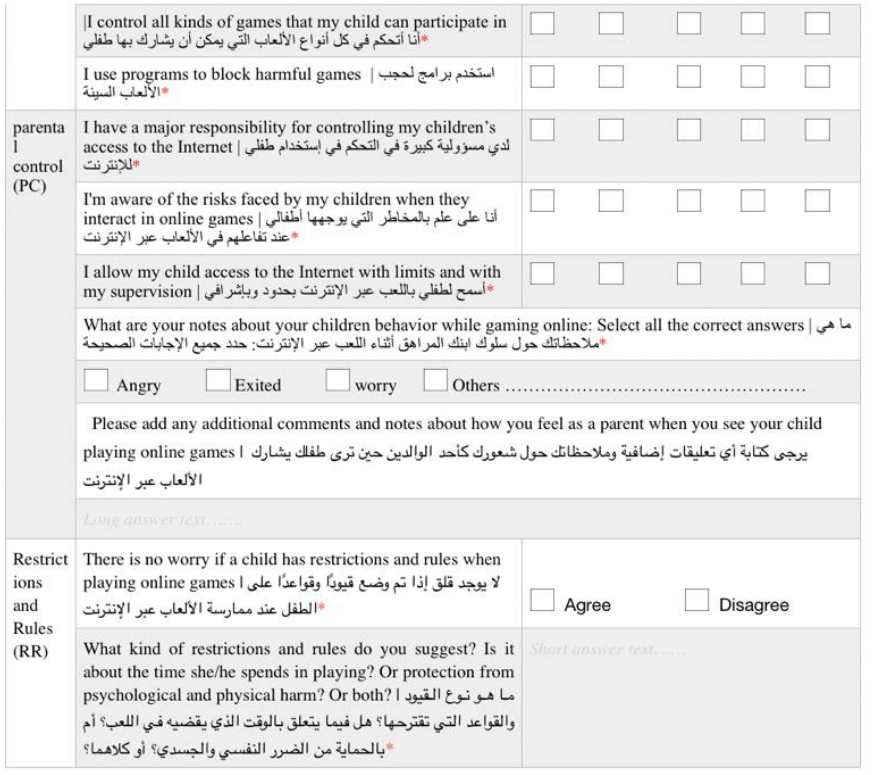

\section{E. Analysis}

1) Structural equation modeling: This study used the modeling of the structural equation, which is a statistical method for testing and estimating causal relationships using a set of statistical data and qualitative causal assumptions. Addictive causal models and linear support theoretically can be tested using a tool in research called SEM like PLS, it was done by measured the items and then statistically tested. Usually one or more hypotheses are required that are represented as a model (see Fig. 1 and Table III).

2) Proposed model: The following model was developed.

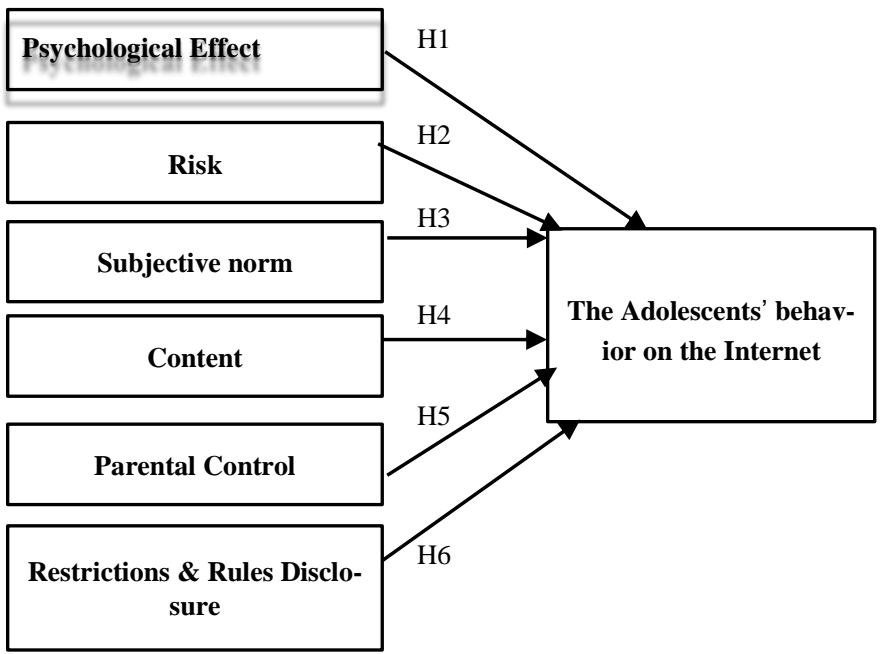

Fig. 1. Conceptual Framework and Hypotheses (Model A). 


\section{3) Proposed Hypothesis}

TABLE III. DEFINITIONS OF T HYPOTHESIS

\begin{tabular}{|c|c|}
\hline$H 1$ & $\begin{array}{l}\text { Internet gaming addiction fears will affect children's online behav- } \\
\text { ior. }\end{array}$ \\
\hline $\mathrm{H} 2$ & $\begin{array}{l}\text { Information disclosure will have a positive effect on the level of } \\
\text { privacy concerns. }\end{array}$ \\
\hline$H 3$ & Privacy risk will have a positive effect on online gaming addiction \\
\hline H4 & $\begin{array}{l}\text { parental control will have a negative effect on the level of addiction } \\
\text { to online games }\end{array}$ \\
\hline H5 & The subjective norm will have positive effect on teen addiction \\
\hline H6 & Internet content will have a negative impact on teenagers \\
\hline
\end{tabular}

4) Data preparation for smartPLS: In this study, the participants' results were manually entered in Microsoft Excel and saved as xlsx format as shown in Fig. 2. This data set contains a sample size of 1500 without any missing values, invalid observations, or outliers. The first row of the Excel spreadsheet has the names of these indicators, such as (AHB, $\mathrm{PE}, \mathrm{R})$, to ensure that the software can correctly import the file data. Because SmartPLS can- not take the Excel file format directly, the file has been converted to the appropriate extension for the data set, which is .csv format.

5) Building the inner model: A proposed model for this study was designed (see Fig. 1) and it is a basic model based on which an internal model will be built. An internal model can be created easily in the SmartPLS program by representing latent variables by red circles, after drawing circles it is possible to change the default name by right- clicking on each latent variable. In order to link these variables together, arrows are drawn by clicking on the arrow symbol in the menu (see Fig. 3).

6) Building the outer model: The indicators are pulled from the "indicators" tab to the corresponding red circle, in order to link the latent variable and thus build an outer model. When the link is established, the color of the latent variable will change from red to blue. By right-clicking on the blue variable, indicators can be easily moved on the screen using the "Align Top / Bottom / Left / Right" function (see Fig. 4).

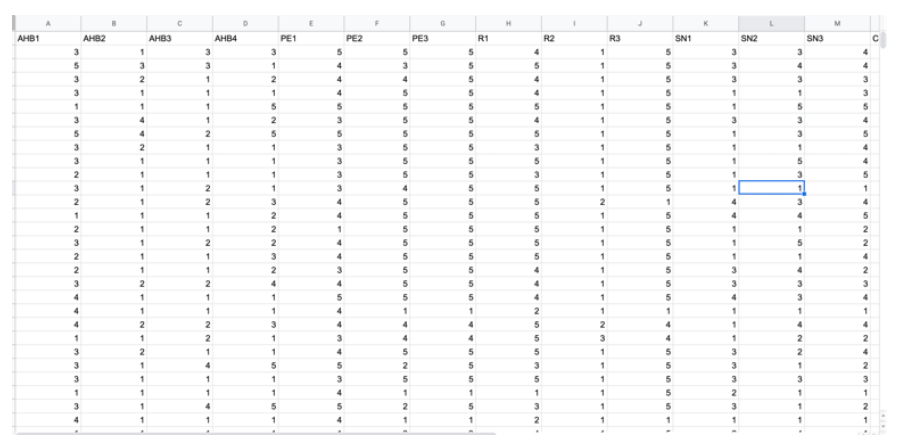

Fig. 2. Dataset from our Survey.

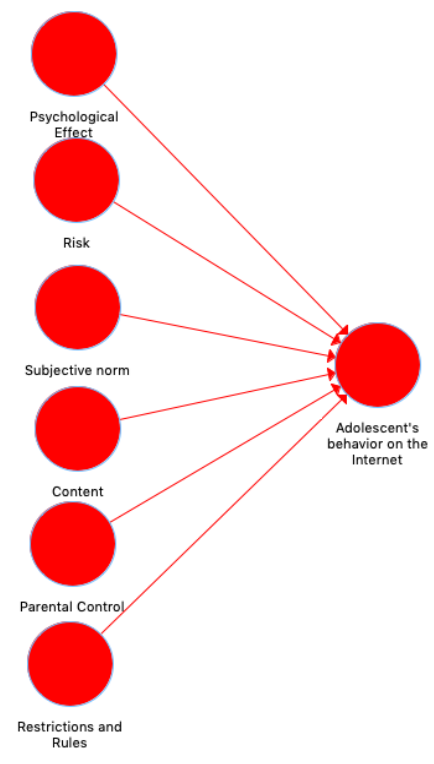

Fig. 3. Building the Inner Model.

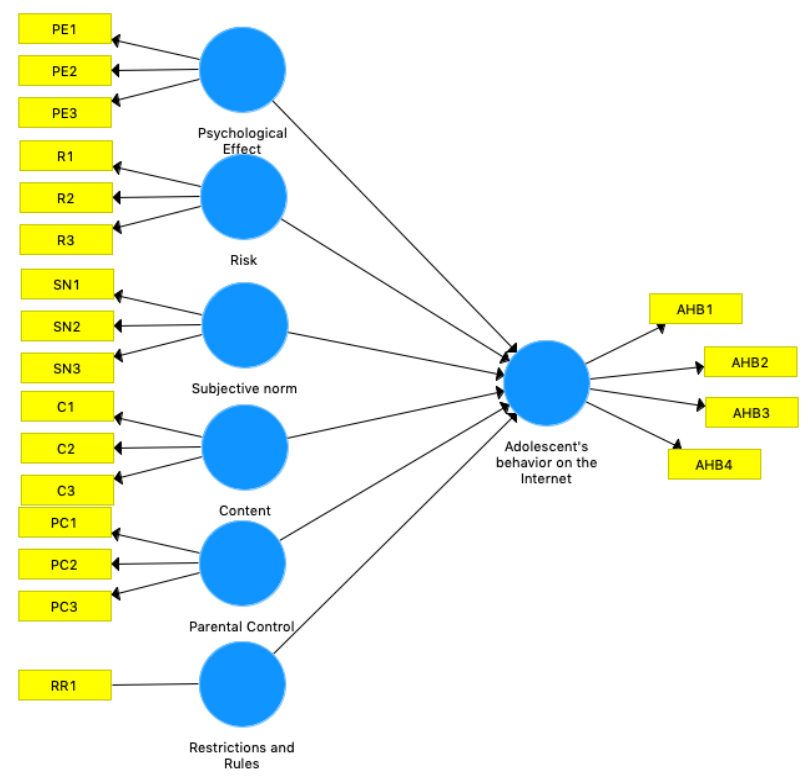

Fig. 4. Building the Outer Model.

7) Running the Factor-Modeling Estimation: The factor modeling procedure can be implemented, by going to the "Calculate" menu and choosing "PLS Algorithm" and then successfully linking the indicators and latent variables together in the SmartPLS with no red circles and arrows. As a result that there is no missing value for the data set in this study, we proceed directly to configure the settings of the PLS algorithm with the following parameters: Scheme.

a) Weighting Scheme will be: Factor Weighting

b) Data Metric will be: Mean 0, Variance 1.

c) Maximum Iterations will be: 300 .

d) Abort Criterion will be: $1.0 \mathrm{E}-5$.

e) Initial Weights will be: 1.0 (see Fig. 5). 


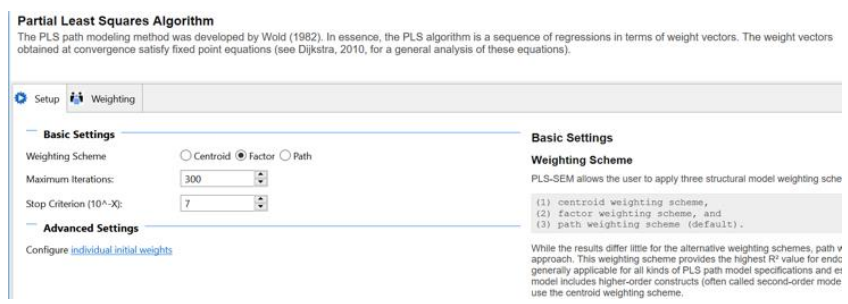

Fig. 5. Configuring the PLS Algorithm.

8) Assessing the PLS Output: SmartPLS text-based report estimates provide path modeling that can be accessed via the Report menu not only in the Modeling window (see Fig. 6).

9) Structural model evaluation: Then, we validate the suggested model for modeling the process specified in the hypotheses.

10)Inner model path coefficient sizes and significance: Results are shown based on the suggested inner model that the Restrictions and Rules has the strongest effect on Adolescents' behavior on the internet (0.261), followed by Parental Control (0.119), subjective norms (0.046), Psychological Effect ($0.016)$, Content $(-0.245)$ and the weakest effect is Risk on (0.505). Thus we can conclude that Restrictions and Rules, Parental Control and subjective norms are moderately strong predictors of Adolescents' behavior on the internet, but the opposite of the factors Psycho- logical Effect, Content and Risk.

11) Outer model loadings: The following table shows the correlations between the latent variable and indicators in its outer model (Table IV).

12)Indicator reliability: All other research considers that the reliability and validity of the latent variables are essential to complete the examination of the structural model. The above table outlined the various items of reliability and validity that must be examined and reported when performing the PLS-SEM.

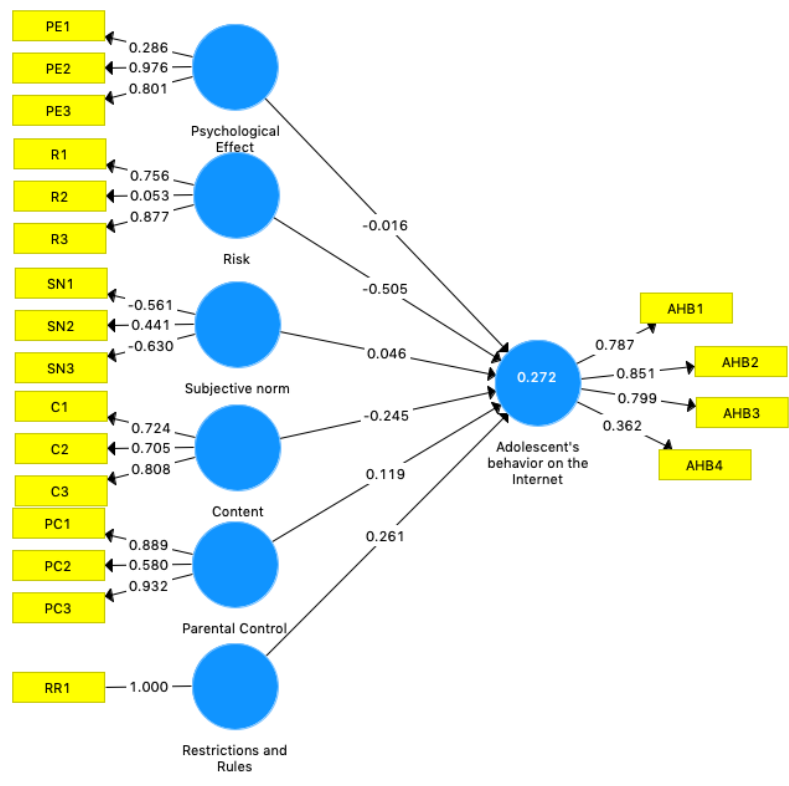

Fig. 6. PLS Results.
TABLE IV. RESUlt SUMMARY FOR REFLECTIVE OUTER MODELS

\begin{tabular}{|l|l|l|l|l|l|l|}
\hline & AVE & CR & $\begin{array}{l}\text { Cranach's } \\
\text { Alpha }\end{array}$ & $\begin{array}{l}\text { Item } \\
\text { Loading }\end{array}$ & Mean & Load- ing \\
\hline PE & $\begin{array}{l}0.66 \\
8\end{array}$ & $\begin{array}{l}0.7 \\
32\end{array}$ & 0.509 & $\begin{array}{l}\text { PE1 PE2 } \\
\text { PE3 }\end{array}$ & 3.013 .64 & 0.8750 .896 \\
\hline R & $\begin{array}{l}0.84 \\
1\end{array}$ & $\begin{array}{l}0.9 \\
41\end{array}$ & 0.905 & R1 R2 R3 & $\begin{array}{l}3.253 .35 \\
3.56\end{array}$ & $\begin{array}{l}0.9300 .921 \\
0.900\end{array}$ \\
\hline SN & $\begin{array}{l}0.78 \\
0\end{array}$ & $\begin{array}{l}0.9 \\
14\end{array}$ & 0.859 & SN1 SN2 & $\begin{array}{l}3.993 .85 \\
\text { SN3 }\end{array}$ & $\begin{array}{l}0.8830 .884 \\
0.882\end{array}$ \\
\hline C & $\begin{array}{l}0.57 \\
4\end{array}$ & $\begin{array}{l}0.7 \\
99\end{array}$ & 0.641 & C1 C2 C3 & $\begin{array}{l}2.553 .18 \\
3.21\end{array}$ & $\begin{array}{l}0.6070 .810 \\
0.835\end{array}$ \\
\hline PC & $\begin{array}{l}0.69 \\
8\end{array}$ & $\begin{array}{l}0.8 \\
74\end{array}$ & 0.788 & $\begin{array}{l}\text { PC1 PC2 } \\
\text { PC3 }\end{array}$ & $\begin{array}{l}3.803 .37 \\
3.55\end{array}$ & $\begin{array}{l}0.822 \\
0.847\end{array}$ \\
\hline RR & $\begin{array}{l}0.59 \\
0\end{array}$ & $\begin{array}{l}0.7 \\
32\end{array}$ & 0.354 & RR1 & 2.88 & 0.925 \\
\hline
\end{tabular}

Composite Reliability (CR): composite ratability effect between 0.7 and 0.8 is considered normal, if either the value does not exceed -0.5 or 0.06 then there is a problem. 0.9 or above is great.

Cronbach's Alpha: It is always considered valid except if the value in the study is less than 0.5 .

13)Checking structural path significance in bootstrapping: To test the importance of both inner and outer models, we create T-statistics by SmartPLS and using a procedure called bootstrapping. Let's do this by selecting "Bootstrapping" from the "Calculate" menu (see Fig. 7 and Table V).

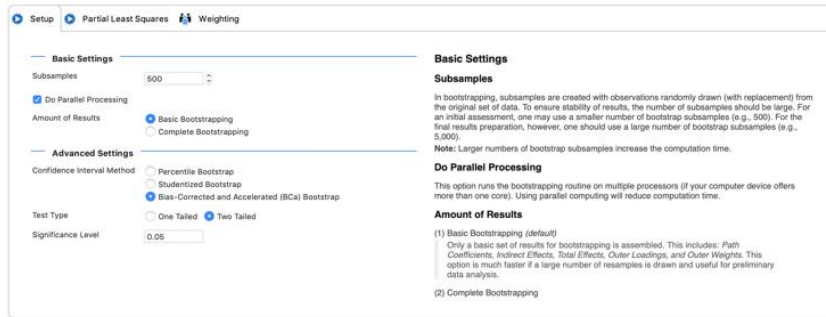

Fig. 7. Bootstrapping Algorithm.

TABLE V. RESUlts of THE STRUCtURAL Model AND HyPOTHESES TESTING

\begin{tabular}{|l|l|l|l|}
\hline Hs & Associations & Coefficients & Supported \\
\hline H1 & PE > AHB & 0.199 & Yes \\
\hline H2 & R > AHB & 0.546 & Yes \\
\hline H3 & SN > AHB & 0.681 & Yes \\
\hline H4 & C > AHB & 0.254 & Yes \\
\hline H5 & PC > AHB & 0.099 & Yes \\
\hline H6 & RR $>$ AHB & 0.014 & Yes \\
\hline
\end{tabular}

If the effect between two constructs in the model is less than 0.05 , there are not support, Otherwise sup- port. The findings of the study indicate that:

$\mathrm{H} 1: \mathrm{PE}>\mathrm{AHB}$ is support.

$\mathrm{H} 2$ : $\mathrm{R}>\mathrm{AHB}$ is support.

H3: $\mathrm{R}>\mathrm{AHB}$ is support. 
H4: C > AHB is support.

H5: $\mathrm{PC}>\mathrm{AHB}$ is support.

H6: RR > AHB is support.

14)Study demography: Below are the results of the pre-test questionnaire (see Table VI):

TABLE VI. STUDY DEMOGRAPHY

\begin{tabular}{|l|l|l|}
\hline Demography Variable & Demography Classification & Frequency \\
\hline Gender & Female Male & 990510 \\
\hline Age & $18-2425-3435-4445+$ & $\begin{array}{l}24600665 \\
211\end{array}$ \\
\hline Education & $\begin{array}{l}\text { High school Bachelor No } \\
\text { degree Others }\end{array}$ & $\begin{array}{l}412876186 \\
26\end{array}$ \\
\hline Parent? & Yes No & 15000 \\
\hline & & 321 \\
& & 550 \\
405 \\
190 \\
Children
\end{tabular}

\section{RESULT}

The Adolescents' behavior on the Internet, Psychological Effect, Risk, Subjective Norm, Content, Parental Control, and Restrictions and Rules, Scale was used in our evaluation as an overall score. The questions from this survey were always completely relevant, making this test rather practical on these points. We have used it in its broadest sense as we try to find the factors that lead to addictive behavior in adolescents in online games on a more formal and uniform level. In the previous part, we saw the analysis of the questionnaire using smart SPL tool and in the next part we will dis- cuss the hypotheses through the view of the end-users who participated in the performance of the experiment:

\section{A. Psychological Effect}

The study found that Information disclosure had a positive effect on the Privacy concerns $(\beta=0.199)(\mathrm{H} 1)$.

The result partly showed the extent to which parents are concerned about the negative effects of either the bad games or the bad people they interact with on the Internet. With average scores, we found that overall scores were varied, although they were closely related to each other, which can be seen through an illustration in the previous section. The difference in scores is relative where the participants' total support was $80 \%$ concerned that their children were gaming online.

\section{B. Risk}

The study found that Information disclosure had a positive effect on the Privacy concerns $(\beta=0.546)(\mathrm{H} 2)$.

The result shows that participants' awareness of risks poses a positive impact on their perception of the risk of their adolescent's addiction to game online. This result confirms the hypothesis of this study. This indicates that the greater the awareness of parents in monitoring their children, the fewer risks involved. It was recorded that there was a similarity in the score by all the participants, who recorded that they were interested in the nature of the games their children interacted with online.

\section{Subjective Norm}

The study found that Information disclosure had a positive effect on the Privacy concerns $(\beta=0.681)(\mathrm{H} 3)$.

The result of the factor shows that subjective standards will have a negative impact in relation to privacy concerns. As this result appears in a varying percentage between that the children of the participants tend to share their information, while the people who interact with them do not show all of their information, this may be because users who voluntarily dis- close personal information are associated with their behavior as a result of the confidence they have gained with other users of the network. This finding also con- firms the results of previous studies that found subjective criteria positively associated with privacy concerns.

\section{Content}

The study found that Information disclosure had a positive effect on the Privacy concerns $(\beta=0.199)(\mathrm{H} 4)$.

The result in the content factor showed a slight difference between the opinions of parents on the extent of their control over the content, but the highest percent- age of $85 \%$ stressed the importance of controlling the content of the games, as this confirmed that they are aware of the risks and implications of that, so they emphasized their use of blocking programs.

\section{E. Parental Control}

The study found that Information disclosure had a positive effect on the Privacy concerns $(\beta=0.254)$ (H5).

The result here confirms that the participants have strict control over their children and the study con- ducted in different societies may show close results. With a difference of $90 \%$ of parents are aware of the risks that their children can face and how important it is to monitor their children and allow them to game online under their supervision.

\section{F. Restrictions and Rules}

The study found that Information disclosure had a positive effect on the Privacy concerns $(\beta=0.099)$ (H6).

The last factor is the Restrictions and Rules, which gave a difference in the result by the participants, where $80 \%$ of the participants recorded their support for establishing rules and restrictions when children game online, and some participants commented by $7.4 \%$ the importance of establishing restrictions and rules to protect against psychological harm, in When $3.6 \%$ of the respondents recorded the importance of establishing restrictions and rules to protect against physical harm, while the highest vote was $73 \%$, the importance of establishing restrictions and rules to protect against psychological and physical harm together.

1) The Adolescents' behavior on the Internet: The result recorded by the participants in this factor confirms the importance of the role of parents in reducing the risks of their children using the Internet, as the biggest difference in the result was given by the participants in the first point of the adolescent behavior factor on the Internet, who recorded that 
they have no objection to the use of their children The Internet in the event that there is no danger to them, and within certain time limits. The result of this factor shows that there is nothing wrong with using the Internet under certain conditions that parents place on their children such as time as well as the element of safety, this result is consistent with what we have reached, and the reason may be that our participants may have strict control over their children.

\section{CONCLUSION}

The main objective of this study was to reduce the risk of adolescent addiction in online games by under- standing and analyzing factors that influence their behavior in order to achieve the goal, and this study was developed as a model and measured adolescent perceptions from a parent's perspective. The study uses smartPLS to analyze results. This study discusses the hypothesis and the results of the research. Finally, it ends with contributions and future work.

The research question is: What factors have influenced teen addiction to online games? To answer this question, some objectives were raised as follows:

- Study the primary role of parents in allowing their children to use the Internet and monitor their behavior while playing online, and what procedures are followed accordingly.

- To study parents' awareness of their children's behavior while playing online.

- Focus on adolescents when they use the Internet for games by reducing the risks of influencing their behavior.

- Provide a comprehensive explanation of how to assess factors that influence addiction behavior, especially adolescents, in order to help protect them from the psychological harm that many games may cause.

- To describe a method for measuring parenting concerns about their children's addiction to Internet games through an effective quantitative research application.

This study was designed to serve the community in protecting adolescents from the harm of internet gaming addiction. In addition, the study contributes to educating and awareness parents about the importance of protecting their children from the dangers of the Internet by contacting them and obtaining their opinions on the behavior of teenagers on the Internet. This study provides support for parents to make the Internet safer and more secure for their children. Since this study provided observations related to protecting the privacy of information for adolescents and examining some of the factors that can influence their behavior, these topics will be of interest to researchers and practitioners in the public domain. This study inevitably faced many limitations. We will then summarize the limitations of this study and identify proposed further improvements for future research. This study needs to identify more factors. Some items did not achieve the desired value resulting in deletion. Depending on the limitations we mention, future work can be: The study may involve and test more factors like trust, trust in the Internet, and the risk of making friends while gaming online.

\section{ACKNOWLEDGMENT}

I would like to thank Allah for all the blessings that I have. A special thanks to supervisor Dr. Hedia Zardi for her help and for her directions for this paper.

\section{REFERENCES}

[1] S. Livingstone and D. R. Brake, "On the rapid rise of social networking sites: New findings and policy impli- cations," Adolescents \& society, vol. 24, no. 1, pp. 75-83, 2010.

[2] F. Annansingh and T. Veli, "An investigation into risks awareness and e-safety needs of adolescents on the in- ternet: a study of Devon, UK," Interactive Technology and Smart Education, vol. 13, no. 2, pp. 147$165,2016$.

[3] M. O. Lwin, A. D. Miyazaki, A. J. Stanaland, and E. Lee, "Online usage motive and information disclosure for preteen adolescents," Young Consumers, vol. 13, no. 4, pp. 345-356, 2012.

[4] S. Bannon, T. McGlynn, K. McKenzie, and E. Quayle, "The Internet and young people with additional support needs (ASN): Risk and safety," Computers in Human Behavior, vol. 53, pp. 495-5032015.

[5] A. Alkhalifah and J. D'Ambra, "Identity Management Systems Research: Frameworks, Emergemce, and Fu- ture Opportunities," in ECIS, 2015.

[6] J. Bryce and J. Fraser, "The role of disclosure of person- al information in the evaluation of risk and trust in young peoples' online interactions," Computers in Hu- man Behavior, vol. 30, pp. 299-306, 2014.

[7] E. Aghasian, S. Garg, L. Gao, S. Yu, and J. Mont- gomery, "Scoring users' privacy disclosure across multi- ple online social networks," IEEE access, vol. 5, pp. 13118-13130, 2017.

[8] K. Li, Z. Lin, and X. Wang, "An empirical analysis of users' privacy disclosure behaviors on social network sites," Information \& management, vol. 52, no. 7, pp. 882-891, 2015.

[9] W. Shin and N. Ismail, "Exploring the role of parents and peers in young adolescents' risk taking on social networking sites," Cyberpsychology, Behavior, and So- cial Networking, vol. 17, no. 9, pp. 578-583, 2014.

[10] T. Buchanan, C. Paine, A. N. Joinson, and U. D. Reips, "Development of measures of online privacy concern and protection for use on the Internet," Journal of the American society for information science and technolo- gy, vol. 58, no. 2, pp. 157-165, 2007.

[11] Z. De Souza and G. N. Dick, "Information disclosure on MySpace-the what, the why and the implications," Pas- toral Care in Education, vol. 26, no. 3, pp. 143-157, 2008.

[12] N. K. Lankton, D. H. McKnight, and J. F. Tripp, "Face- book privacy management strategies: A cluster analysis of user privacy behaviors," Computers in Human Behav- ior, vol. 76, pp. 149-163, 2017.

[13] C. S. Silva, G. A. Barbosa, I. S. Silva, T. S. Silva, F. Mourão, and F. Coutinho, "Privacy for Adolescents and Teenagers on Social Networks from a Usability Perspec- tive: A Case Study on Facebook," in Proceedings of the 2017 ACM on Web Science Conference, 2017, pp. 63-71: ACM.

[14] K. Li, X. Wang, K. Li, and J. Che, "Information privacy disclosure on social network sites: An empirical investi- gation from social exchange perspective," Nankai Busi- ness Review International, vol. 7, no. 3, pp. 282-300, 2016.

[15] X. Zhang, L. Zhang, and C. Gu, "Security Risk Estima- tion of Social Network Privacy Issue," in Proceedings of the 2017 the 7th International Conference on Communi- cation and Network Security, 2017, pp. 8185: ACM.

[16] J. Bremer, "The internet and adolescents: advantages and disadvantages," Child and Adolescent Psychiatric Clinics, vol. 14, no. 3, pp. 405-428, 2005.

[17] J. Wojniak and M. Majorek, "Adolescents in internet space-the European Union policies on adolescents's safety online," in SHS Web of Conferences, 2016, vol. 26, p. 01048: EDP Sciences. 